\title{
INFLUÊNCIA DO PLÁSTICO BRANCO, PODA VERDE E AMINO QUELANT®-K NA QUALIDADE DE PÊSSEGOS ‘SANTA ÁUREA’ $\left({ }^{1}\right.$ )
}

\author{
RENATO TREVISAN $\left({ }^{2 *}\right)$; EMERSON DIAS GONÇALVES $\left({ }^{3}\right)$; RAFAEL DA SILVA GONÇALVES $\left({ }^{4}\right)$; \\ LUIS EDUARDO CORRÊA ANTUNES $(2,5)$; FLAVIO GILBERTO HERTER $\left({ }^{2,5}\right)$
}

\begin{abstract}
RESUMO
A qualidade das frutas é determinada por fatores relacionados ao clima, solo, cultivar, as práticas culturais adotadas, época e forma de colheita e processos de manipulação da fruta na pós-colheita. Uma das formas de melhorar esta qualidade é a utilização de práticas de manejo na pré-colheita. Assim, este trabalho teve por objetivo avaliar o efeito do plástico branco, da poda verde e do nutriente aminoquelant ${ }^{\circledR}-$ K, associado ou não ao tratamento com plástico branco e poda verde, na qualidade de pêssegos 'Santa Áurea'. Os atributos de qualidade avaliados foram: percentagem visual de vermelho, intensidade de vermelho na epiderme, determinada pelo sistema CIEL*a* $b^{*}$, massa, diâmetro, firmeza de polpa, sólidos solúveis totais (SST), acidez total titulável (ATT) e relação SST/ATT. As práticas utilizadas causaram o aumento do percentual de vermelho na epiderme das frutas; o aminoquelant ${ }^{\circledR}-\mathrm{K}$ isolado proporcionou maior acidez das frutas; a melhor relação SST/ATT foi obtida com o uso do plástico branco sob a copa e pela combinação do plástico com o nutriente aminoquelant@-K.
\end{abstract}

Palavras-chave: Prunus persica, poda verde, cor de fundo, aminoquelant ${ }^{\circledR}-\mathrm{K}$.

\section{ABSTRACT \\ INFLUENCE OF WHITE PLASTIC, VEGETATIVE PRUNING AND AMINO QUELANT-K ON QUALITY OF PEACHES ‘SANTA ÀUREA'}

Fruit quality is influenced by climate, soil, cultivar, orchard management, time of harvesting and fruit handling at harvest and post harvest. One way of improving the fruit quality is through cultural practices. Thus, this work had the objective of evaluating the effect of the white plastic, vegetative pruning and aminoquelant ${ }^{\circledR}-K$, alone or the combination of the last with plastic or summer pruning, on the quality of peaches cv. Santa Aurea. The quality attributes evaluated quality were: visual percentage of red on the fruit surface, intensity of red in the epidermis, determined by the CIEL*a* $b$ * system, fruit mean weight, diameter and firmness, total soluble solids (TSS) content on the flesh, total titratable acidity (TTA) and the relation TSS/TTA. All the tested treatments increased the percentage of red on the fruit epidermis; the use of aminoquelant ${ }^{\circledR}-\mathrm{K}$, alone, resulted in greater acidity of the fruits; the best relation TSS/TTA was obtained by the use of the white plastic under the canopy and by the combination of that plastic with aminoquelant ${ }^{\circledR}-\mathrm{K}$

Key words: Prunus persica, green prunning, back ground color, aminoquelant ${ }^{\circledR}-\mathrm{K}$

(1) Recebido para publicação em 27 de abril de 2006 e aceito em 20 de agosto de 2007.

( $\left.{ }^{2}\right)$ Embrapa Clima Temperado, BR 392, km 78, Caixa Postal 403, 96001-970 Pelotas (RS). E-mail: renatrevisan@gmail.com $\left(^{*}\right)$ Autor para correspondência. Bolsista EV-CNPq; antunes@cpact.embrapa.br; herter@cpact.embrapa.br

$\left({ }^{3}\right)$ EPAMIG, Fazenda Experimental de Maria da Fé, Rua Washington Viglione, 2300, Bairro Vargedo, 37518-000 Maria da Fé (MG). E-mail: emersondg@gmail.com

(4) Graduando em Agronomia, Universidade Federal de Pelotas, FAEM-UFPel, Caixa Postal 354, Pelotas (RS). E-mail: rsgagro@pop.com.br

$\left({ }^{5}\right)$ Bolsista PQ/CNPq. 


\section{Introdução}

O mercado brasileiro para frutas de clima temperado é bastante promissor, porém é carente, tanto em volume de produção como em qualidade de frutas. A questão da qualidade está intimamente relacionada à qualificação da mão-de-obra empregada no processo produtivo, uma vez que o sucesso das inovações tecnológicas depende da sua correta aplicação. Ademais, as necessidades do consumidor final devem ser de conhecimento de todos os agentes da cadeia produtiva, inclusive dos produtores, que, no manuseio correto das frutas, contribuem para o melhor desempenho do setor. No Brasil, tais questões normalmente não são observadas, comprometendo, sobretudo, a apresentação do produto e aumentando as perdas.

O Estado do Rio Grande do Sul, conforme dados da Empresa Brasileira de Pesquisa Agropecuária, é o principal produtor brasileiro de pêssegos, com cerca de $46 \%$ da produção nacional, ocupando uma área superior a 10 mil hectares. $\mathrm{O}$ município de Pelotas concentra mais de $90 \%$ da produção de pêssegos destinados ao processamento no País (Sebrae, 2007). Desta produção, aproximadamente, apenas $5 \%$ destina-se ao consumo in natura. Apesar deste pequeno percentual, muitas vezes essas frutas são apresentadas aos consumidores com qualidade visual deficiente. Sendo assim, qualquer intervenção (manejo na planta) que venha a ser realizada na pré-colheita é pertinente, desde que não prejudique as qualidades físico-químicas das frutas.

A cultivar Santa Áurea tem como genitor feminino a cultivar Cerrito, e masculino a seleção NJC 88 , oriundo do programa de melhoramento da Universidade de Rutgers, New Jersey, EUA. Esta cultivar, tipo indústria, possui pouca coloração vermelha na epiderme, porém, tem bom tamanho e teor de sólidos solúveis totais, e poderia, portanto, ser comercializada para consumo in natura. Dessa forma, são justificáveis técnicas de manejo que potencializem características de aparência neste cultivar, como por exemplo, a coloração da epiderme.

A poda verde, realizada na pré-colheita, é uma técnica de manejo empregada com a finalidade de aumentar a radiação solar no interior da planta (CoutinHo et al., 2005), melhorando assim algumas características das frutas como cor, tamanho, sólidos solúveis e sabor. Por outro lado, o emprego de plásticos refletivos sobrepostos sob a copa das plantas com o objetivo de refletir a luz solar para o seu interior, além de intensificar a coloração vermelha na epiderme das frutas, pode antecipar a maturação (TREvisAN et al.,
2006). O potássio quando fornecido às frutíferas, contribui para o aumento da coloração vermelha da epiderme, do tamanho, da firmeza de polpa e do sabor, da uniformização dos frutos, do valor nutritivo, do conteúdo de minerais e da antecipação da maturação (TReVisan, 2006; Bioiberica, 2006).

Desta forma, o trabalho teve como objetivo avaliar o efeito do plástico branco, da poda verde e do aminoquelant ${ }^{\circledR}-\mathrm{K}$, sozinho ou na combinação com o plástico branco e poda verde, na qualidade de pêssegos 'Santa Áurea'.

\section{Material e Métodos}

O trabalho foi desenvolvido com frutas de um pomar comercial localizado no município de Pelotas/RS, da safra de 2004/2005. Utilizaram-se 96 plantas, considerando-se 48 plantas úteis da cultivar Santa Áurea, plantadas em vaso aberto, e espaçadas de $6 \times 2 \mathrm{~m}$. Os tratamentos aplicados foram: 1) Plástico branco: superfície do solo das plantas úteis coberto com manta de plástico branco $\left.\left(16 \mathrm{~m}^{2}\right) ; 2\right)$ Poda verde: eliminação de ramos ladrões no interior da copa e base do tronco; 3) Aminoquelant ${ }^{-}-\mathrm{K}$, composto de $30 \%$ de $\mathrm{K}_{2} \mathrm{O}$ e $5 \%$ de aminoácidos livres: dose recomendada pelo fabricante de $350 \mathrm{~mL} / \mathrm{ha}$; foram realizadas três pulverizações com intervalos de 8 dias; 4) Plástico branco + aminoquelant ${ }^{\circledR}-\mathrm{K}$; 5) Poda verde + aminoquelant ${ }^{\circledR}-\mathrm{K}$; 6) Testemunha: plantas sem intervenção fitotécnica. Todos os tratamentos foram realizados 40 dias antes da data prevista para a colheita.

A colheita foi realizada em 15/12/2004 e foram coletadas aleatoriamente 15 frutas por repetição, para as seguintes avaliações: a) Intensidade visual da cor vermelha na epiderme (IVV): determinada visualmente, atribuindo-se notas (zero: sem cor vermelha na epiderme; nota 1: até $25 \%$ de cor vermelha na epiderme; nota 2: entre $25 \%$ a $50 \%$ de cor vermelha na epiderme, nota 3: entre $50 \%$ a $75 \%$ de cor vermelha na epiderme e nota 4 : entre $75 \%$ e $100 \%$ de cor vermelha na epiderme das frutas; b) Cor da epiderme pelo sistema CIEL*a* $\mathrm{b}^{*}$ : determinada através do colorímetro eletrônico, Minolta 300, com iluminante D 65 e abertura de $8 \mathrm{~mm}$. Neste sistema de representação de cor, os valores de $L^{*}, a^{*}$ e $b^{*}$ descrevem a uniformidade da cor no estado tridimensional, em que $\mathrm{L}^{*}$ corresponde ao escuro brilhante $\left(0\right.$, preto; 100 , branco), os valores de $a^{*}$ correspondem à escala do verde ao vermelho $\left(a^{*}\right.$ negativo, cor verde; $\mathrm{a}^{*}$ positivo, vermelho) e os valores de $b^{*}$ correspondem à escala do azul ao amarelo $\left(b^{*}\right.$ negativo, cor azul; $b^{*}$ positivo, amarela). A partir desses valores, calculou-se o ângulo Hue $\left(h^{\circ}\right)$ pela 
formula $h^{0}=\tan ^{-1} b^{*} / a^{*}$. Foi efetuada uma leitura na maior intensidade de cor vermelha na epiderme de cada fruta; c) tamanho das frutas: medido diretamente com auxílio de um paquímetro digital colocado em posição perpendicular ao eixo da fruta, expresso em milímetros; d) massa: obtida por pesagem das 15 frutas por tratamento em balança digital, expressa em $\mathrm{Kg}$; e) Firmeza da polpa das frutas: determinada utilizando-se um penetrômetro manual, com ponteira plana de $8 \mathrm{~mm}$ de diâmetro. Foram efetuadas duas leituras por fruta, em lados opostos na região equatorial, após a remoção de uma pequena e superficial porção da casca, sendo os resultados expressos em Newtons (N); f) sólidos solúveis totais (SST): determinado por refratometria, e os resultados expressos em ${ }^{\circ}$ Brix; g) acidez total titulável (ATT): determinada pela titulação potenciométrica com $\mathrm{NaOH} 0,1 \mathrm{~N}$ até $\mathrm{pH} 8,10$ de $10 \mathrm{~g}$ da amostra triturada em $90 \mathrm{ml}$ água destilada. Os resultados foram expressos em percentagem (\%) de ácido cítrico; h) relação entre sólidos solúveis e acidez total titulável.

O delineamento experimental utilizado foi em blocos ao acaso com quatro repetições, utilizando duas plantas como unidade experimental e duas plantas como bordadura. As médias foram comparadas pelo teste de Duncan a 5\% de probabilidade de erro. Foi utilizado o programa estatístico SANEST.

\section{Resultados e Discussão}

A intensidade da cor vermelha na epiderme das frutas, avaliada visualmente, foi maior nas frutas do tratamento poda verde $(13,6 \%)$, não diferindo significativamente dos tratamentos com plástico branco mais aminoquelant ${ }^{\circledR}-\mathrm{K}(11,2 \%)$ e poda verde mais aminoquelant ${ }^{\circledR}-\mathrm{K}(10,8 \%)$, respectivamente (Tabela 1). Nas frutas do tratamento-testemunha ocorreu menor intensidade visual de vermelho, $6,0 \%$. Entretanto, pelo sistema CIEL*a* $\mathrm{b}^{*}$, nos frutos das plantas que tiveram intervenções (manejo) na précolheita, os valores médios de $\mathrm{a}^{*}$, não diferiram estatisticamente entre si, porém, todos diferiram da testemunha (Tabela 1). Esse fato caracteriza que tanto visualmente, como pelo sistema CIEL ${ }^{*}{ }^{*} b^{*}$, foi possível observar que nas plantas onde não foi realizado nenhum tratamento (manejo), as frutas obtiveram menor cor vermelha na epiderme. Porém, cabe relatar que nenhum tratamento (manejo) proporcionou coloração vermelha na epiderme igual ou acima de $50 \%$. Quanto ao ângulo Hue, apesar de ser a variável que melhor representa a evolução da cor na epiderme, não se observou diferença estatística significativa entre os tratamentos realizados (Tabela 1).
Tabela 1. Intensidade visual da cor vermelha (IVV) e coloração da epiderme pelo Sistema CIEL*a*b* de pêssegos cultivar Santa Áurea de plantas submetidas a diferentes tratamentos pré-colheita

\begin{tabular}{|c|c|c|c|}
\hline \multirow{2}{*}{ Tratamentos } & \multirow[b]{2}{*}{$\operatorname{IVV}(\%)$} & \multicolumn{2}{|c|}{ Sistema CIEL*a*b* } \\
\hline & & $a^{*}$ & Hue \\
\hline Plástico branco & $9,6 \mathrm{~b}$ & $16,4 a$ & $72,1 \mathrm{a}$ \\
\hline Poda verde & $13,6 \mathrm{a}$ & $18,2 \mathrm{a}$ & $64,0 \mathrm{a}$ \\
\hline Aminoiquelant ${ }^{\circledR}-K$, & $7,8 \mathrm{~b}$ & $14,2 \mathrm{a}$ & 54,6 a \\
\hline $\begin{array}{l}\text { Plástico branco } \\
+ \text { Aminoiquelant®-K }\end{array}$ & $11,2 \mathrm{ab}$ & $17,5 a$ & $68,0 \mathrm{a}$ \\
\hline $\begin{array}{l}\text { Poda verde } \\
+ \text { Aminoiquelant } ®-K\end{array}$ & $10,8 \mathrm{ab}$ & $16,4 a$ & $66,4 \mathrm{a}$ \\
\hline Testemunha & $6,0 \mathrm{c}$ & $11,0 b$ & 54,6 a \\
\hline Média geral & 18,1 & 18,2 & 66,9 \\
\hline CV (\%) & 11,5 & 6,5 & 23 \\
\hline
\end{tabular}

Médias seguidas de pelo menos uma letra igual não diferem entre si. Ângulo Hue ( $0^{\circ}$ vermelho; $90^{\circ}$ amarelo; $180^{\circ}$ verde).

Vários estudos têm mostrado que a disponibilidade de luz adicional para as plantas, seja com poda verde, seja com o uso de material refletivo no solo, entre fileiras ou abaixo da copa, intensifica a coloração vermelha na epiderme de pêssegos e maçãs (LAYNe et al., 2001; TREvisAn et al., 2006). Francisconi et al. (1996) e Trevisan et al. (2006) observaram efeito significativo no incremento da coloração vermelha na epiderme de pêssegos ao realizarem poda verde. TREVISAN et al., (2004) também observaram incremento da cor vermelha na epiderme das frutas ao disporem plástico de ráfia sob a copa das plantas de pessegueiro cv. Eldorado. Para Ju et al. (1999) este aumento da coloração vermelha na epiderme é conseqüência da ação dos plásticos ao refletirem a luz, pois estimulam a síntese das antocianinas, as quais aceleram a expressão do gene para a enzima flavonóide-3-o-glicosil transferase, responsável pela formação da pigmentação vermelha.

Apesar de os frutos das plantas submetidas aos diferentes tratamentos terem atingido tamanhos aparentemente maiores que podem, em princípio, ser classificados como do tipo CAT I (diâmetro > 57 $\mathrm{mm}$ ), do que as plantas-controle, que poderiam ser classificadas como do tipo CAT II (48 a $57 \mathrm{~mm}$ ) (Tabela 2), as diferenças entre eles não foram estatisticamente significativas. Assim, os resultados discordam dos de Trevisan et al., (2006) que ao realizarem poda verde, e colocarem plástico metalizado e de ráfia sob a copa das plantas, bem como aplicação de diferentes doses de potássio incorporadas ao solo e pulverizadas na folha, obtiveram um aumento significativo no tamanho das frutas. 
Tabela 2. Tamanho, massa, firmeza, SST, ATT e SST/ATT de pêssegos cultivar'Santa Áurea' de plantas submetidas a diferentes tratamentos pré-colheita

\begin{tabular}{|c|c|c|c|c|c|c|}
\hline Tratamentos & Tamanho & Massa & Firmeza & SST & ATT & SST/ATT \\
\hline & $\mathrm{mm}$ & $\mathrm{kg}$ & $\mathrm{N}$ & ${ }^{\mathrm{o}}$ Brix & $\%$ & \\
\hline Plástico branco & $65 a$ & $2,1 \mathrm{a}$ & $9,8 \mathrm{a}$ & $11,6 a$ & $0,68 \mathrm{c}$ & $16,9 \mathrm{a}$ \\
\hline Poda verde & 59 a & $1,7 \mathrm{a}$ & $11,5 \mathrm{a}$ & $11,3 a$ & $0,78 \mathrm{~b}$ & $14,5 \mathrm{bc}$ \\
\hline Aminoiquelant ${ }^{\circledR}-\mathrm{K}$, & $62 \mathrm{a}$ & $1,7 \mathrm{a}$ & 11,3 a & $11,2 \mathrm{a}$ & 0,88 a & $12,7 \mathrm{c}$ \\
\hline Plástico branco + Aminoiquelant ${ }^{\circledR}-\mathrm{K}$ & 65 a & $2,1 \mathrm{a}$ & $9 a$ & $11,8 \mathrm{a}$ & $0,77 \mathrm{~b}$ & $15,4 \mathrm{ab}$ \\
\hline Poda verde + Aminoiquelant ${ }^{\circledR}-K$ & $62 \mathrm{a}$ & $1,9 \mathrm{a}$ & $11 \mathrm{a}$ & $11,3 a$ & $0,81 \mathrm{ab}$ & $13,8 \mathrm{bc}$ \\
\hline Testemunha & $55 \mathrm{a}$ & $1,5 \mathrm{a}$ & $11,8 \mathrm{a}$ & $11,5 \mathrm{a}$ & $0,85 \mathrm{ab}$ & $13,4 \mathrm{c}$ \\
\hline Média geral & 61 & 1,8 & 10,7 & 11,5 & 0,79 & 14,5 \\
\hline CV (\%) & 23 & 21,6 & 13,9 & 4,3 & 3,6 & 7,9 \\
\hline
\end{tabular}

Médias seguidas de pelo menos uma letra igual não diferem entre si.

Segundo MARINI (2006), o potencial máximo em tamanho ocorre em regiões da copa da planta que recebem até $20 \%$ de luz direta nas últimas três semanas que antecedem à colheita, o que justificaria o uso do plástico sob a copa das plantas e poda verde, que auxiliam na produção de carboidratos pelo processo fotossíntético, aumentando o tamanho das frutas. O potássio, provavelmente por expandir as células e ativar várias enzimas, proporcionaria igualmente aumento do tamanho das frutas.

A massa, a firmeza de polpa e os sólidos solúveis totais não foram influenciados significativamente pelos tratamentos aplicados (Tabela 2). Jaeger e Putter, (1999) e Francisconi et al. (1996) também não observaram diferenças significativas ao utilizarem, respectivamente, plástico refletivo, potássio e poda verde em macieira e pessegueiro.

A maior acidez foi verificada em frutas dos tratamentos que envolveram potássio. Alguns autores relatam que esse mineral pode aumentar a acidez das frutas quando disponibilizado às plantas, pois é encontrado em quantidades elevadas em todos os tecidos da planta. A menor porcentagem de acidez foi observada nas frutas do tratamento com plástico branco sob a copa das plantas. Esse pode ser explicado porque, provavelmente, o plástico ao refletir a luz solar, aumenta a temperatura no interior da planta (TARARA, 2000), acelera a maturação e, conseqüentemente, eleva a relação SST / ATT. MEREDITH et al., (1989) relatam que para a fruta ser considerada de alta qualidade, a relação SST/ATT deverá ser maior ou igual a 15, o que foi constatado nos tratamentos com plástico branco isolado e combinado com aminoquelant ${ }^{\circledR}-\mathrm{K}$ (Tabela 1$)$. TREVISAN (2006) também verificou aumento na relação quando utilizou plástico metalizado sob a copa das plantas em pessegueiros cv Maciel.

\section{Conclusões}

1. A poda verde, o plástico branco e o aminoquelant ${ }^{\circledR}-\mathrm{K}$, isolados ou associados entre si, podem ser empregados para aumentar a coloração na epiderme das frutas.

2. Os tratamentos utilizados não têm efeito sobre tamanho, massa, firmeza e sólidos solúveis totais.

3. $\mathrm{O}$ aminoquelant ${ }^{\circledR}-\mathrm{K}$ proporciona frutas mais ácidas e com menor relação SST/ATT, enquanto com o uso do plástico branco obteve-se maiores relações SST/ATT.

\section{Agradecimentos}

Os autores agradecem à Fundação de Amparo à Pesquisa do Estado do Rio Grande do Sul (FAPERGS), pelo apoio financeiro dado ao projeto 04/ 0579-9, e ao Conselho Nacional de Desenvolvimento Científico e Tecnológico e (CNPq) pela concessão de bolsa de Recém-doutor, projeto 304172/03-0.

\section{Referências}

BIOIBERICA. AminoQuelante-K. Fisiologia Vegetal. Disponível em: <http://www.bioiberica.com/fisiologiavegetal/ aminoquelantk.htm>. Acesso em: 13 de fevereiro de 2006.

COUTINHO, E.F.; FRANCHINI, E.R.; CAMELATTO, D.; ULGUIM, E.B. Relação entre a poda verde e o uso de material refletivo com a qualidade de pêssego 'Eldorado'. Pelotas: Embrapa Clima Temperado, 2005. 21 p. (Embrapa Clima Temperado. Documentos, 134)

FRANCISCONI, A.H.D.; BARRADAS, C.I.N.; MARODIN, G.A.B. Efeito da pode verde na qualidade do fruto e na produção de pessegueiro cv. Marli. Pesquisa Agropecuária Brasileira. Brasília, v.31, n.1, p.51-54, 1996. 
JAEGER, A; PUTTER, H. Preharvest factors and postharvest quality decline of apples. Acta Horticulturae, Wageningen, v.485, p.103-110, 1999.

JU, Z.; DUAN, Y.; JU. Z. Coloration potential, anthocyanin accumulation and enzyme activity in fruit of commercial apple cultivars and their F1 progeny. Scientia Horticulturae, Amsterdam, v.79, p.39-50, 1999.

LAYNE, D.R.; JIANG, Z.; RUSHING, J.W. Tree fruit reflective film improves red skin coloration and advances maturity in peach. HortTechnology, Alexandria, v.11, n.2, p.234-242, 2001.

MARINI, R. How o grow big peachs: Fruit and vegetable convetion and trade show. Hershey, Pennsylvania. Disponível em: http://www.rce.rutgers.edu/peach/orchard/ bigpeaches.pdf. Acesso em: 27 de janeiro de 2006.

MEREDIT, F.I.; ROBERTSON, J.A.;HOVART, R.J. Changes in physical and chemical parameters associatedwith quality $\mathrm{d}$ postharvest ripening of harvests peaches. Journal Agricultural and Food Chemistry, Washington, v.37, n.5, p.1210-1214, 1989.
SEBRAE. Agência sebrae de notícias RS. Produtores de pêssegos buscam tecnologias na serra. Disponível em: <http:// $\mathrm{s}$ e b r a e r s 2. i n t e r j o r n a l. c o m. b r / noticia.kmf?noticia $=5689363 \&$ c a nal $=225 \&$ total $=340 \&$ indice $=20>$ Acesso em: 01 de março de 2007 .

TARARA, J.M. Microclimate modification with plastic mulches. HortScience, Alexandria, v.35, p.169-180, 2000.

TREVISAN, R.; GONÇALVES, E. D.; COUTINHO, E. F. Qualidade de pêssegos em pomares conduzidos de forma convencional e integrada. Ciência Rural, Santa Maria. v.34, n.6, p.1747-1751, dez 2004.

TREVISAN, R.; HERTER, F.G.; COUTINHO, E.F.; GONÇALVES, E.D.; SILVEIRA, C.A.P.; FREIRE, C.J.da S. Uso de poda verde, plásticos refletivos, antitranspirante e potássio na produção de pêssegos. Pesquisa Agropecuária Brasileira, Brasília, v.41, n.10, p.1485-1490, out. 2006. 